\title{
Addressing design and suitability barriers to Telecare use: Has anything changed?
}

\author{
Claire L. Bentley ${ }^{\mathrm{a}, *}$, Lauren A. Powell ${ }^{\mathrm{a}}$, Alison Orrell ${ }^{\mathrm{b}}$ and Gail A. Mountain ${ }^{\mathrm{a}}$

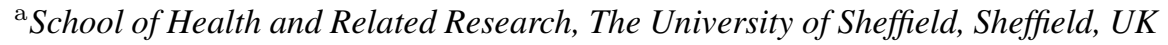 \\ ${ }^{\mathrm{b}}$ School of Social Sciences, Neuadd Ogwen, Bangor University, Bangor, Gwynedd, Wales, UK
}

\begin{abstract}
.
BACKGROUND: Issues relating to design and suitability of Telecare were raised twenty years ago. We explored the views of non-users of Telecare and examined whether design-related barriers exist today despite significant technological advances.

OBJECTIVE: To examine the reasons why people choose not to adopt Telecare, with specific focus on reasons relating to design and suitability of the intervention.

METHODS: Individual qualitative semi-structured interviews were conducted with people who were not using or had actively declined Telecare, a voice which is rarely heard in Telecare-barrier research. Framework analysis was used to identify existing and emergent themes for $n=22$ participants.

RESULTS: Sub-themes relating to design and suitability of Telecare were explored: Stigma, i.e. Telecare as symbolising old age and lost independence; Design, including stigmatising aesthetics and inappropriate use; Alternative options, i.e. propensity to seek non-Telecare solutions; Awareness of the devices and service; and Cost.

CONCLUSIONS: Barriers to Telecare use are similar for both users and non-users. Our results indicate that design-related barriers have yet to be addressed despite the technological revolution. The cost model of Telecare services is becoming more consumer-driven. Thus Telecare design needs to exploit technological advances in order to improve wellbeing and allow individuals their choice and independence.
\end{abstract}

Keywords: Telecare, barriers, stigma, independence

\section{Introduction}

The term Telecare comprises technology which is used to alleviate the risks of independent living through the automatic and passive monitoring of an individual's environment and/or lifestyle [1].

Telecare is viewed as being a key solution to the increased burden placed on social care resources by the ageing population and increased morbidity [2]. Those who are positive about Telecare report that the technology has the potential to save lives and improve care, through reducing unplanned hospital admissions and

*Corresponding author: C.L. Bentley, School of Health and Related Research, The University of Sheffield, Regent Court, 30 Regent Street, Sheffield S1 4DA, UK. Tel.: +44 0114222 2976; E-mail: c.bentley@sheffield.ac.uk. reducing the likelihood of care home admission [3], allowing older people to live safely and independently at home [4], and complementing the work of informal carers and social care professionals [2]. Telecare has been widely promoted through various UK Government campaigns to try and encourage increased uptake [2]3]. However many people who could potentially benefit from Telecare choose not to use it [5].

\subsection{Development of Telecare}

Telecare was first introduced in the 1940s as a means of summoning help in residential homes through pressing a buzzer. This was superseded by speech-based systems in the 1960s and subsequently by first generation Telecare systems (e.g. the pendant alarm) in the 1980s [46]. In 1992 Thornton and Mountain [7] con- 
ducted a detailed UK-based mixed-methods investigation into uptake of Telecare, its operation, how the service fitted into the wider context of community-based social care provision, and what users and providers thought of it. The results showed that the Telecare service was generally perceived in a positive way by service users, offering peace of mind for both the recipients and their family members. However the authors also identified several factors relating to the design and suitability of Telecare which negatively impacted upon its perception and use. These factors included:

- The assumption that Telecare meets the needs of, and is appropriate for, all users in all situations;

- Limited awareness and understanding of the service, among both service users and providers, and even after installation;

- Assumptions underpinning the service (e.g. that users will wear their pendant alarm at all times) removing personalisation and being antagonistic to choice and independence;

- Design flaws relating specifically to the pendant alarm, including discomfort, obstruction of normal activities and propensity for accidental triggering, with the result that many people did not wear them (even if a lighter one was provided);

- Over or under use of the service, possibly due to misunderstandings regarding the situations which the service was intended for, and through users not wanting to be a burden even when help was needed.

Thornton and Mountain [7] predicted that advances in technological design and innovation would help to address some of these issues, for example through habit cycle monitoring. The authors noted that manufacturers had responded to criticisms of the pendant alarm by developing wrist and brooch style triggers. They predicted that future Telecare users would benefit from technological advances, better understanding of the service, and greater flexibility in service provision.

\subsection{The current situation}

Second generation Telecare allowing the automatic detection of limited alert conditions, such as flood detectors and falls detectors, were introduced in the late 1990s [468]. This has been followed by third generation Telecare, which provides additional support capabilities such as lifestyle monitoring and interaction (e.g. over the internet) [9], although this is deemed as a potential invasion of privacy by potential users [10]. Since 1990 the digital revolution has rapidly acceler- ated, leading to greatly increased availability and use of the Internet, computers and mobile phones, as well as other technological advancements [11]. Since 2010 mobile tablets, which have touchscreen interfaces and which allow various multi-media functions, have become widely available [12]. Advancements in technology were predicted by Thornton and Mountain in 1992 [7], and this raises the question whether, twenty years down the line, anticipated improvements in Telecare design and service delivery have in fact taken place.

\subsection{The current research}

Numerous studies have been conducted since 1992 which have investigated perceived benefits and barriers of Telecare among Telecare service users. However there has been little research investigating these perceptions among people who are not using Telecare. Boström et al. [13] highlighted that participants using monitoring technology might have biased perceptions towards it as they have (arguably) accepted the technology in their daily lives. Sanders et al. [5] did attempt to unpick barriers to Telecare use among individuals who had refused it as part of the Whole Systems Demonstrator study. This, however, was in the context of a randomised controlled trial, in which case the study design itself may have been a barrier.

Although an increased range of Telecare solutions has become available in recent years uptake remains relatively low [14], thus there is a need to further explore the reasons why people decline to use Telecare services. In April 2012 Telecare referral rates in one northern city in the UK had seen a gradual decline over the previous twelve months. The Local Authority for the region operates in conjunction with a private company to deliver a 24-hour Telecare-based monitoring and response service for the region. Referrals are typically received from health and social care staff, through family members, or through self-referrals. A wide range of ages and circumstances are catered for, and a range of first and second generation Telecare devices are provided. In most cases the service is selffunded, although when the current study was initiated third sector funding was available to cover the costs of Telecare for the most vulnerable members of the community. The local Telecare providers operate a pricing system whereby a basic weekly cost (approximately $£ 4.80$ ) is paid for a lifeline unit and pendant alarm, with a small additional weekly cost (50p-£1.50) for any additional Telecare items (accurate March 2014). 
Prices were similar, although marginally lower, when the study was initiated in 2012.

An opportunity arose to explore the reasons for reduced referral rates in the region. A collaborative project was established between the research team, the Local Authority and the company who provide the service, to investigate barriers to Telecare adoption among non-users of Telecare.

The specific aims of the project described in this paper were:

- Primary Aim: To examine the reasons why people choose not to adopt Telecare when it may be an appropriate intervention in their circumstances (e.g. if they have a disability)

- Secondary Aim: To explore peoples' perceptions of the most effective messages and modes for service providers to successfully communicate the benefits of Telecare to users and potential users

The findings concerned with issues of design and suitability of Telecare are reported here.

\section{Methods}

\subsection{Design}

We conducted a qualitative study incorporating individual semi-structured interviews with people who were non-users of Telecare. This design was chosen to allow in-depth exploration of contextual and situated personal accounts, knowledge, experiences and preferences in relation to the research aims. Definitions and case studies were used to provide examples and create a common understanding of Telecare within the context of the interviews.

\subsection{Recruitment}

We targeted individuals aged 18 years and over who were not currently receiving Telecare but who may have been deemed to benefit because of their age and/or personal circumstances. Although the sample was opportunistic, as would be expected the majority of those who were identified and interviewed were aged 65 years and over. Individuals who had been referred to the local Telecare provider and had later declined the service were sent a letter by the provider inviting them to participate in the study to discuss their decision with the independent research team. In addition we aimed to recruit non-users of Telecare who had not necessarily refused it outright, in order to gain a multi-faceted perspective on the research aims. We anticipated situations in which an individual might be deemed to benefit from Telecare but had never become known to the service, had never considered it as an option, or did not know of its existence. These individuals were targeted using advertisements in local newspapers and in community/third sector publications. The research team also visited relevant local community meetings and gatherings to talk about the research and invite people to take part. Participants were to be excluded if there were doubts about whether they would be able to provide informed consent (e.g. dementia, severe learning difficulties), although exclusion on this basis did not occur. Participants were offered a $£ 10$ monetary incentive for taking part.

\subsection{Participants}

In total twenty-two participants were recruited (fifteen female; seven male). Two participants declined to give their age. Six participants were under 65 years of age, eleven were aged between $65-80$ years, and three were aged 81 years or over. Those who volunteered to be interviewed had variable living situations and personal circumstances (see Table 1 for more information).

\subsection{Materials}

An interview guide and associated interview materials were developed by the research team in conjunction with the Local Authority and local Telecare providers. These materials were then checked by members of a Trust-convened patient participation panel for relevance and comprehensiveness for a lay audience, and minor wording changes were made as a result. The guide contained a list of questions to address the research aims, whilst allowing flexibility to deviate from the guide or question order, depending on the flow of the conversation. The guide broadly addressed the following areas:

1. Participants' previous experiences of and knowledge of Telecare (if any)

2. Perceived relevance of Telecare to themselves

3. Perceived advantages of Telecare

4. Perceived disadvantages of Telecare

5. Overall opinion of Telecare

6. Changes which could be made to the service which would make it more suitable/appealing

7. Messages around Telecare which might make it appealing to themselves and others 
8. How they would improve awareness of Telecare services and where they would go for information

After checking the participant's understanding/experiences of Telecare, they were provided with the following definition of Telecare - "the use of technology to help people remain safe and independent in their own home" (in accordance with the local definition). They were then shown four example scenarios (adapted from locally-used Telecare case studies) of people and situations for which Telecare might be suitable, along with illustrations and descriptions of various Telecare devices mentioned within the scenarios. The scenarios included older people with memory/mobility problems, a younger individual with learning difficulties, an able-bodied older person wishing to use Telecare for peace of mind, differing levels of family influence, and different types of housing. We anticipated low awareness of Telecare among participants, thus the scenarios were essential in providing a common understanding of Telecare and a context for the discussion of its advantages and disadvantages.

\subsection{Procedure}

Interviews took place in the participant's home, in a public location (e.g. café), or over the telephone, depending on the preference of the participant. Use of the interview materials was adjusted depending on the location and mode of the interview, e.g. Telecare scenarios were read out to participants over the phone for telephone interviews. An information sheet containing details about the study was sent to participants at least a week prior to the interview. Written or recorded verbal informed consent was obtained at the beginning of each interview, before any data were collected. All interviews were conducted by two researchers and ranged in length from 17-95 minutes long. Demographic data were captured during the interview.

\subsection{Data analysis}

Twenty of the interviews were digitally recorded and transcribed verbatim. One participant declined permission for audio recording, and the recorder failed at the start of another interview. In both of these instances detailed notes were taken instead. We conducted Framework analysis [15] to understand both the overall picture of barriers to Telecare adoption, and each individual's circumstances and decision making process. Two researchers independently familiarised themselves with the data and independently identified emergent themes. They then devised and agreed the coding framework. The interviews were coded in accordance with the framework using a software analysis tool (NVivo 9), and any discrepancies in coding were discussed and resolved together. Each theme and each participant's decision process was then summarised, with relevant quotes being drawn out, and higher level interpretation applied.

The current paper focuses on themes relating to the design and suitability of Telecare. Whilst we have included quotes and/or examples from most of the participants, we were not able to specifically discuss each individual's decision process within the current paper. A future publication is planned which will explore the Telecare acceptance/refusal decision process in more detail.

\subsection{Ethics}

Ethical approval for the research was gained from The University of Sheffield's School of Health and Related Research (ScHARR) Ethics Committee. Appropriate governance approvals were gained from the relevant Local Authority.

\section{Results}

\subsection{Participant characteristics}

Participants (identified via pseudonyms) varied widely in their personal circumstances (see Table 1). One participant had been offered a six week free trial of Telecare by the local provider but had refused this. Two participants were living in sheltered housing with Telecare included but held negative opinions about it and did not use it. The rest of the participants were recruited through local media, voluntary and community organisations and had never used Telecare. Participants varied widely in their living and family circumstances, health status, and past and present informal caring responsibilities.

\subsection{Design and suitability}

The sub-themes presented here are those which relate to the over-arching theme of Design and Suitability. The five sub-themes are: Stigma; Design; Awareness; Alternative Options; and Cost. 
Table 1

Breakdown of participants' individual circumstances

\begin{tabular}{|c|c|c|}
\hline Name & Age & Circumstances \\
\hline 'Lily' & 82 & $\begin{array}{l}\text { Offered a } 6 \text { week free trial after recent admission but refused } \\
\text { Widowed, lives alone } \\
\text { Daughter living nearby, trying to persuade her to have Telecare } \\
\text { Mobility restrictions }\end{array}$ \\
\hline 'Tina' & 61 & $\begin{array}{l}\text { Lives with husband } \\
\text { Carer for her mother, trying to persuade her to have Telecare } \\
\text { Hearing impairment } \\
\text { Members of husband's family are Telecare users } \\
\text { Most of family live locally } \\
\text { Husband has a heart condition }\end{array}$ \\
\hline 'Norman' & 67 & $\begin{array}{l}\text { Lives alone } \\
\text { Regularly looks after his grandchildren, family live locally } \\
\text { Diabetic } \\
\text { Sister uses Telecare }\end{array}$ \\
\hline 'Robert' & Unknown & $\begin{array}{l}\text { Sheltered housing with Telecare included, negative opinions towards it } \\
\text { Lives alone } \\
\text { Mobility problems and registered blind } \\
\text { Son lives } 40 \text { mins away }\end{array}$ \\
\hline 'Joyce' & 76 & $\begin{array}{l}\text { Diabetic, cancer survivor, hearing impairment, mental health issues } \\
\text { Was a Nurse and then a Health Visitor during career } \\
\text { Widowed, lives alone } \\
\text { Three children, closest over an hour away } \\
\text { Sister and friends living locally }\end{array}$ \\
\hline 'Kathleen' & 83 & $\begin{array}{l}\text { Lives alone } \\
\text { Heart and blood pressure problems, diabetic, thyroid problems } \\
\text { Neighbours look out for her }\end{array}$ \\
\hline 'Wendy' & 65 & $\begin{array}{l}\text { Lives alone } \\
\text { No health conditions } \\
\text { Used to care for her father, persuaded him to have Telecare }\end{array}$ \\
\hline 'June' & 84 & $\begin{array}{l}\text { Family and neighbours using Telecare } \\
\text { Lives with husband - care for each other } \\
\text { Mobility restrictions (back) } \\
\text { Husband is } 88, \text { mobility problems }\end{array}$ \\
\hline 'Malcolm' & 52 & $\begin{array}{l}\text { Living alone but engaged } \\
\text { No health conditions } \\
\text { Fiancée is } 45 \text { and has Crohn's Disease, arthritis, mobility problems }\end{array}$ \\
\hline 'Bertie' & 75 & $\begin{array}{l}\text { Lives with wife (Violet) } \\
\text { Skin cancer, mobility restrictions (legs), liver problem, diabetic } \\
\text { Wife's brother and friends living locally, daughter in Scotland }\end{array}$ \\
\hline 'Violet' & Unknown & Wife of Bertie, cares for him \\
\hline 'Andrew' & 40 & $\begin{array}{l}\text { Lives alone } \\
\text { Mental health issues }\end{array}$ \\
\hline 'Edith' & 71 & $\begin{array}{l}\text { Lives with husband } \\
\text { Has had caring responsibilities but none at present } \\
\text { Osteoarthritis but fairly mobile }\end{array}$ \\
\hline 'Deirdre' & 76 & $\begin{array}{l}\text { Lives with husband } \\
\text { Minor osteoporosis } \\
\text { Fit, healthy and mobile }\end{array}$ \\
\hline 'Georgina' & 71 & $\begin{array}{l}\text { Lives alone } \\
\text { Past brain haemorrhage, history of mini strokes } \\
\text { Arthritis and balance problems }\end{array}$ \\
\hline 'Gary' & 62 & $\begin{array}{l}\text { Lives with wife } \\
\text { Three of their four parents are alive, he and his wife care for them } \\
\text { Has arthritis }\end{array}$ \\
\hline 'Belinda' & 55 & $\begin{array}{l}\text { Living alone in a flat } \\
\text { Had caring responsibilities in the past } \\
\text { Crohn's Disease, bowel cancer }\end{array}$ \\
\hline 'Samuel' & 70 & $\begin{array}{l}\text { Husband of Martha } \\
\text { Prostate cancer, diabetes, neuropathy, stomach problems, hearing loss } \\
\text { Does part time work } \\
\text { Cares for } 93 \text { year old mother }\end{array}$ \\
\hline
\end{tabular}


Table 1, continued

\begin{tabular}{|c|c|c|}
\hline Name & Age & Circumstances \\
\hline 'Martha' & 64 & $\begin{array}{l}\text { Wife of Samuel } \\
\text { Angina } \\
\text { Cares for mother-in-law }\end{array}$ \\
\hline 'Harriet' & 76 & $\begin{array}{l}\text { Living alone } \\
\text { Overactive thyroid, partially sighted, varicose eczema }\end{array}$ \\
\hline 'Rose' & 69 & $\begin{array}{l}\text { Sheltered housing with Telecare included } \\
\text { Right knee replacement, left leg currently injured, possible mini strokes } \\
\text { Mental health issues }\end{array}$ \\
\hline 'Pamela' & 70 & $\begin{array}{l}\text { Living alone in a flat } \\
\text { No relatives close by, eldest son in London, brother in Cleethorpes } \\
\text { Arthritis, thyroid problems, chronic fatigue syndrome }\end{array}$ \\
\hline
\end{tabular}

\subsection{Stigma}

Most of those interviewed associated Telecare with looking and/or feeling old:

\section{"I don't want to feel too old" Lily \\ "I don't consider myself old" Tina \\ "I just think it makes you look like an old per- son... I don't want to appear to look like an old person" Harriet}

There was a sense among these participants that having Telecare would be like giving up and accepting the fact that they are 'old', a feeling which people described trying to resist. This perception is particularly well highlighted by Wendy's observations of her father when he went through the decision process:

\section{"He did resist in having a pendant alarm, I suspect because you are actually having to admit that you are losing it. You are having to recognise in your own self yes I am not the chap I was, I am frail, I am not capable or whatever you are having to admit that and address it rather than ignore it. I could think that a lot of people would just choose to ignore it. I am fine, nothing wrong with me, I'll manage" Wendy}

The pendant alarm appeared to reinforce this stereotype, signalling old age and vulnerability to others. People did not wish to be perceived in this way, and there was minor concern that you could become a target for crime if you were seen wearing the pendant, e.g. by callers at the door. Conversely it was pointed out by one participant that you might be more likely to get help if you have a visual sign of vulnerability.

"I think they might be more vulnerable to outsiders, callers to the door if they saw" Joyce

"If you have got some kind of medical visual thing on you, then they will probably help" Robert
Interestingly many participants were happy to use safety-based technological items which arguably are not as visible and do not have the same stigma attached to them, e.g. installing smoke alarms or carrying a mobile phone. For example, Lily saw the value in having shop-bought smoke alarms installed because she had once left eggs on the stove which boiled dry. Interestingly she was in her forties at the time, thus any association of smoke alarms with old age may have been removed by this incident.

It should be noted that a minority of participants did not perceive that there is a stigma associated with Telecare use, pointing out that younger disabled people also use assistive technology. Some participants were surprised to learn that Telecare can be used in younger populations as well as older ones, although an association with vulnerability remained.

"I mean younger people have all kinds of problems as well don't they where they need help and might need an alarm" Malcolm

The majority of participants acknowledged the potential for Telecare to help people maintain independence and remain at home, although it should be noted that this benefit featured in the definition of Telecare which was provided to participants during the interview.

"Well I would be speaking personally, it would be to maintain independence in your own home" Wendy

"I think things like that, it's brilliant. You know, let them live in their own home in their own surroundings where they are happy and they don't really want to move" Martha

However Telecare was commonly perceived (often by the same participants) as being synonymous with a loss of independence and control, possibly as a result of the stigma surrounding the intervention. 
Phrases such as "reduced quality of life” (Lily), "loss of control" (Tina) and "giving up your independence" (Robert) were frequently used. Interestingly the majority of participants viewed Telecare quite positively however most participants perceived that Telecare was 'suitable for others, but not for me'. When participants listed the types of people they thought might be suitable for Telecare common categories included older people, people with disabilities, and people living on their own. Many of the states listed were associated with the perceived Telecare stereotype of being old, vulnerable, and unable to cope. Most of the participants fitted into at least one of the categories yet still believed Telecare was irrelevant for them personally. When challenged on this they would provide a counterreason for not needing Telecare, e.g. being disabled but not living alone.

"I think it would be advantageous for someone who needed it, who was at greater risk than I am anyway... it's useful for the others, not useful for me I don't need it" Joyce

"Well I feel quite capable as yet" Kathleen

"If I lived on my own possibly, but because I don't live on my own it's not an issue" Tina

"Or somebody who, yes, somebody who was getting older and forgetful. I mean I am getting forgetful but but even more forgetful" Deirdre

"My overall opinion is I think it is very, very good. I am really impressed with those extra things that you have shown me. I think it is very, very good but at the moment not for me, thank you very much" Rose

Wendy had experienced frustration at her father's refusal of the pendant alarm. At the same time she was horrified by the thought of a family member suggesting the pendant alarm to her:

"I would be horrified if someone said that to me because it would be their way of saying to me you are losing it you are not managing or coping and nobody wants to have that said to them" Wendy

A minority of participants did carefully consider their own risk level during the interview, acknowledging the possibility that they were more at risk than they thought. A couple of participants mentioned incidents in which a fairly young and able-bodied person (nonTelecare user), living alone, fell and injured themselves and were fortunate to get help quickly. However this did not appear to change their minds.
"I know people who are perfectly fit who have tripped over and hurt themselves and if they are a long way from a phone, I don't know that's a hard one" Wendy

"I suppose you can make a case for anybody... you don't have to be disabled do you" Tina

Almost all of the participants stated that they would rethink their decision not to use Telecare if their circumstances changed in the future, and some stated that it was advantageous to be aware of these options and to keep them in mind. However importance was placed on the maintenance of independence in making that decision:

"You know I think it is something that I have got in my mind for future use as and when I assess that the risk is at that level... I think I am aware of my own body and would take action, I mean I have done in the past" Joyce

"I think that people are not quite as gullible when they are getting old as what they are made out to be. I do think they are very shrewd about what they require" June

"”Well it could be [relevant], but I mean I don't want it (laughs). But yes it could be, it could be that if I live long enough I might need it because I do know that I have slowed down in these last few years... so yes it could be something that I need to think about" Harriet

\subsection{Design}

The option to wear the alarm button as a wristband rather than a pendant was preferred by most participants as it is more discrete and less stigmatising:

“I mean you don't want something unsightly do you? You know what I mean it's got to be hidden a bit" Norman

"I don't want one of those around my neck... but no I didn't realise that you did one on the wrist and I wouldn't feel so bad about that" Harriet

However a minority of the participants disagreed with this viewpoint, stating that the look of the equipment would be less of a problem in the home environment where it is only yourself and/or your family:

"Why bother, when you are indoors when nobody is watching you anyway you can wear a thing around your neck so whatever happens it's in reach, wherever you are. So why bother just have the pendant" Robert 
The look and feel of certain Telecare items, such as the pendant alarm, can reinforce the stereotype of Telecare as being for people who are 'old' and 'unable to cope'. Wendy described her impressions of design targeted at older people, using mobility aids as an example:

"There are ways to sell things. I think it has got to be cool hasn't it... one of the things that really astonish me, because you don't go into these places unless you need to, the shops that sell mobility aids they are awful, racks of boring looking wheelchairs and Zimmer frame things... it needs to be pulled into the mainstream; these shops need to be made appealing and zippy. Wheelchairs need to be designed, not to look like, well, old people's things. It has to be possible" Wendy

Across the sample design issues were raised regarding a number of specific items of Telecare, especially the more familiar ones. For example, pull cords were often felt to be inappropriately placed so that they might be out of reach if you fell:

"I mean one of the things that I found difficult is that very often they hang from the ceiling... if you were lying on the floor you still can't reach it" Robert

In this sense the pendant alarm design was seen to offer an advantage as help could be summoned wherever you fell. Questions, however, were raised by a couple of participants regarding the range of the alarm and whether someone would be covered on the steps outside their flat. There were also security concerns about the locked access key box placed outside people's homes to allow staff to gain entry to the property in the event of an alert, and worries about needing to remember a code. Joyce was given a mechanical flood failsafe as a free sample by the local Telecare provider, which would not work with her style of sink. Participants with hearing loss did not feel the service offered them anything to help deal with their specific sensory impairment. It was pointed out by a minority of participants that a person with memory problems might not remember to press their alarm, or a person may have a medical event which impairs their physical or cognitive ability to press the alarm.

"When we think about putting these things in, what is their individual circumstances, what is their hearing like, what is their memory like, what is their smell like, is it going to be effective. There is no good assuming because it's an alarm we can put it in and it will solve the problem, because it might not do" Samuel

Accidental triggering of Telecare equipment was raised as an issue. Several participants gave anecdotes from their own experiences in which pull cords had been mistaken for light switches, and another memorable incident in which someone had fallen asleep on their pendant alarm and thus did not answer the operator, which caused a lot of worry. There was also concern about Telecare equipment obstructing normal activities, for example:

"It dangles, it's a nuisance, you could throttle yourself. I mean if he had had that on pruning his roses it would have throttled him" Georgina

Although false alarms and obstruction of activities can undermine the benefits of the technology, June described feeling reassured when a relative's pendant alarm was accidentally triggered and appropriate and swift action was taken by the responders:

"Like the pendant, if my cousin is washing herself around her neck and she happens to catch that button on it, straightaway I have been there and they have rung her up. That is proof to me that somebody is there" June

Instances of inappropriate use of the technology were also reported. Wendy's father had fallen in the bathroom in the middle of the night and had waited until daylight to raise an alert because he did not wish to disturb his relatives. At the other end of the spectrum, a relative of Rose had worked as a Telecare operator she described an incident in which he had responded to an alert raised by a woman who had dropped her sweet on the floor and could not quite reach it.

Interestingly privacy was less of a concern than might be expected. Only Lily referred to Telecare as being "like big brother is watching”, although both she and Pamela were concerned that the assessment and installation process could be intrusive on a person's privacy.

A minority of participants were aware of recent advances in Telecare-related technology. Joyce described hearing about voice prompts for people with dementia if they forgot to close a door, and Wendy and Pamela described third generation Telecare which is aware of your normal movements and detects deviations from the norm:

"I have heard about more sophisticated Telecare where in fact they I suppose computerised your 
known movements what you normally do, like you get up at a certain time, you get up and make yourself a cup of coffee, your moving about your home is recorded and if your habits change this is then picked up" Wendy

"There's all sorts of clever things going on. . . being able to have access through Skype... which seem to me excellent ideas in terms of people not feeling afraid and isolated and being able to make contact, but also mechanisms for the support service to be aware if somebody hasn't got out of their bed for three days" Pamela

One participant had taken part in a different research study looking into using tablets to help people with dementia and with memory problems. Some of the participants had experience of using computers and email, and nearly all of them had a mobile phone. Wendy was considering purchasing a smartphone, and questioned whether or not a smartphone could perform some of the functions carried out by Telecare. However, when asked, participants generally found it difficult to visualise ways in which Telecare design could be improved.

A few of the participants had concerns about the reliability of the equipment and/or the staff operating 'behind' the equipment. Georgina feared that technology was being used to replace contact with people. Anecdotes were given in which Telecare operators did not answer an alarm call straightaway, or in which operators relied too heavily on neighbours being able to call round and check on someone who had raised an alert. It was emphasised that, regardless of the technology, it is essential that it works properly, that people know how to use it and use it appropriately, and that it meets the needs of the individual:

"All technology is useful providing it works and providing people know how to use it" Robert

\subsection{Awareness}

Generally participants knew little about Telecare services prior to being interviewed. Typically where participants had come across Telecare they had heard of pull cords and/or pendant alarms, and the researchers found these to be the easiest examples to use when describing Telecare to participants. There was some awareness that the council were somehow involved in Telecare delivery, and most participants had a general awareness of Telecare as being a means to summon help. Participants who had greater prior knowledge had often been in situations in which a friend or relative had used Telecare, and Joyce had previously seen a stall at an event which had examples of different types of Telecare equipment.

"I have been through the process. I am not quite sure whether people, how easy it would be for people who haven't been through the process" Tina

"He had a range of different things, he showed me the different kinds of alarm things that you can have, you know things that detect whether someone has been out of bed for too long during the night and these sink ones and I can't remember the others but there were a range of them" Joyce

Most participants had not heard the word Telecare and did not associate it with their recollections of pendant alarms/pull cords, even in cases where participants were well-educated, knew of technological developments, or had previously encountered Telecare in their line of work:

"I had previously just called them alarm systems you know personal alarms or something like that. Until you explained what they were, I knew about them but I hadn't made that connection if you understand" Joyce

Participants were often unaware of the range of different types of Telecare, the option to wear the pendant alarm on the wrist, or the use of Telecare in younger populations, yet these were all viewed as key strengths of the service which would heighten the appeal of Telecare if they were known about.

"I certainly didn't know there were any other devices" Kathleen

"Just maybe lack of information and they just haven't heard of Telecare. But I think if they did hear of the product I think they would be impressed" Malcolm

"Well I really only knew about the pendant alarms that you wear around your neck and that you can press when you want to summon help" Deirdre

\subsection{Alternative options}

Many participants used technological alternatives to Telecare. Many of these were devices which are designed to enhance safety, such as smoke alarms, carbon monoxide detectors, and a lid for the oven which cuts off the gas supply when closed. Joyce, who had hearing loss, had obtained a vibrating bed sensor for free from the fire service, which alerts her to the smoke 
alarm sounding. It was also pointed out, in the context of the Telecare scenarios, that a family member could set a thermostat to control the temperature automatically without needing an extreme temperature sensor. Tina's mother had argued that she would rather buy an alarm button which connects directly to her relatives' phone numbers, and another participant had a key safe on the outside of her house with trusted neighbours knowing the combination. These options are cheap or free (often with a one-off payment) rather than paying to maintain a call centre and monitoring service; they are readily available (e.g. from hardware shops); and are easily installed and maintained (either by the participant or by a relative).

The use of a mobile phone, both to contact relatives and to carry around in case of an emergency, was a key alternative strategy to Telecare use.

"My mobile phone has got an emergency button on the back. All I have to do is press that, goes straight through to my son, he is aware that I have got problems, he can ring me and find out" Robert

It was suggested by Wendy that advances in mobile technology may even allow many of the Telecare functions to be carried out via smartphones. Most participants had a mobile phone (although some had it reluctantly and only used it for emergencies). The advantages of a mobile phone were its ability to contact people and its portability, advantages which are comparable to the pendant alarm. Disadvantages included the fact that help would not be as instant as with Telecare. In addition Joyce reported that she often forgot to carry her phone with her as she did not feel the need to; a scenario resonant of the pendant alarm. A general disadvantage of alternative technological options was their increased reliance on family members being in a position to answer and act on a call for help, which might not be possible or practical:

"Mine is my home address and I'm not in I'm talking to you and she could be laid on the floor couldn't she. So whilst she sees it's a better idea, and I can agree with her financially, she can't get her head around the fact that we are not sat at the side of the phone all day. We are still fairly active" Tina

A couple of participants indicated that they were very self-sufficient and recognised for themselves when they needed to take action. In these situations they weighed up the advantages and disadvantages of the different options and made their own informed choice as part of their maintaining independence:
"The next thing I thought of was carrying my mobile phone around with me, it's not as instant as a Telecare system but for the risk that I believe I am at, at the moment I thought that was sufficient but it has fallen out of use because I don't see, you know my assessment of the risk at the moment is not very high” Joyce

\subsection{Cost}

Monetary cost to the individual was raised as a significant barrier to Telecare use. This was felt by the majority of participants to be too high, especially when considering the fact that many older people are surviving on a basic pension. If your pension is feeding you and heating your home then you are not likely to forego those essentials to be able to have Telecare, especially if you do not feel it is needed or if it is used infrequently.

“It’s $£ 4.50$ a week I think, £20 a month, for some
people they can't afford that” Norman
"They seem to think that 20 or something pound
a month is not a lot to pay out of a pension but
you see my experience is that people don't see how
relative money is. People who have got it seem to
think it isn't much" Samuel
"That's the big worry, that as charges go up people
will try and manage without the services to their
detriment” Belinda

However a minority of participants felt that the price was reasonable:

"It doesn't seem too bad to be quite honest, it doesn't. When you think what peace of mind you are getting from it I don't think it's too bad... I suppose if you have not got it and it's hard to find it's a different kettle of fish, but they can't afford to be giving everything away all the time can they?" Harriet

The majority of participants were not aware of the cost of Telecare. Those who were, or who had the pricing structure explained to them, occasionally felt the structure was too complicated.

"But you see that again is my mum's argument that's a cost, that's a cost, if it was just a package $£ 5$ a month but then you have to finalise your own needs and then each one is an extra £1 something or whatever" Tina 
There was evidence of a Cost (including, but not limited to, monetary cost) versus benefit decision process in people's decisions to use or not use Telecare. Essentials such as food and utilities were prioritised, followed by items and activities which were perceived to be of most value in maintaining independence and quality of life. If the perceived need for Telecare is high enough then a person may be more willing to pay for the intervention, unless they really cannot afford it. However if the high cost (including, but not limited to, monetary cost) is not justified then people will not pay for it.

"It just seems to me I don't know disproportionate to you know for someone who is fairly fit and would only infrequently use it in real emergencies. I don't believe I am at that stage yet" Joyce

"And it's the same with this Telecare, you look at it first to see if it's better than the other or equal to the other and then you have to look at the price to see whether you are interested in that one or that one" Norman

"You have got to see it in the same light as insurance, because that is what it is really, it's insurance" Georgina

"The fact that I'm not doing anything about it is I still think I'm relatively young and I still think I'm managing... it would be an extra cost on my budget" Pamela

"But the fact that tomorrow she might need it and it's not there, you have got to weigh up the advantages and the disadvantages" Martha

\section{Discussion}

The results presented in this paper are based on a qualitative investigation into barriers to Telecare use, with a specific focus on issues relating to the overarching theme of Design and Suitability of the technology and associated service. Twenty years prior to this research Thornton and Mountain [7] identified a number of design-related barriers to Telecare use, including limited awareness and understanding of the technology and the service, design flaws (e.g. relating to the pendant alarm), and inappropriate use of the technology. Our findings indicate that many of these barriers still exist today despite significant technological advancements and some efforts by manufacturing companies to improve Telecare design, for example those described by Milligan et al. [16]. Our research also shows that barriers to Telecare use are similar for both users and non-users of the service.

\subsection{Stigma}

People do not want to be stigmatised [13]. In contrast to Thornton and Mountain [7], one theme which emerged strongly from our data was the association of Telecare with increased age, vulnerability and inability to cope. Growing older was viewed negatively by our participants and was a phenomenon which was resisted for as long as possible. Telecare is frequently advertised as a means to maintain independence, yet paradoxically participants commonly associated Telecare with reduced rather than enhanced independence. Another finding was that whilst participants had positive perceptions of Telecare, they did not perceive Telecare as being relevant for themselves even when they fitted into one or more of the categories of eligibility that they themselves gave. Participants were stating that Telecare was 'suitable for others but not for me'. Acceptance of Telecare is synonymous with accepting that you are old, ill and dependent, which is difficult to accept.

Our findings support previous research in that Telecare is often perceived as an actual threat to a person's independence, identity, and ability to look after themselves [5 17], and may even be perceived as bringing them closer to the care home or death [18]. People will often distance themselves from negative connotations of old age, dependence and ill-health, for example by comparing themselves to others who are felt to have greater need for help [517].

\subsection{Design}

Stigma is not only a major barrier for Telecare use but is also inherent in the design of many Telecare systems, for example in the obstructiveness and symbolism of the pendant alarm and the general outmoded appearance of devices for older people. The design of the pendant alarm lends itself to accidental triggering and inappropriate use, e.g. refusal to wear. Furthermore, the fundamental design has not changed since Thornton and Mountain's 1992 [7] study and remains in common use despite the development of wrist-worn options, of which most of our participants were unaware. In addition, a high volume of accidental triggering can lead to abandonment of the technology or perceived intrusion of the technology in people's daily lives [4 [18].

In 2007 the Office of National Statistics (ONS) [11] reported that computer and internet use were higher in younger age groups (people aged less than 55 years) than in older age groups (people aged 55 years and 
over). There may be several reasons for this, including a lack of perceived need to use the internet, a lack of knowledge and confidence in using it, and income disparities [11 19]. The digital revolution has brought with it significant changes in the way technology looks, works, acts and reacts to the user. These changes may have led to frustrations for older people in trying to use them, particularly when coupled with changes in capabilities resulting from the ageing process [19].

However the same ONS survey also highlighted that the 55-64 year age group showed the greatest increase in internet use. Fisk et al. [19] reported that usability issues are often shared among all age groups, and that when usability is improved for older adults it is generally improved for younger adults too. Older people use a wide range of technologies and hold varying, but mostly positive, opinions about them [19]. If a person (regardless of age) perceives that use of a particular piece of technology will provide benefit(s) for them then they are more likely to use it, thus it is a myth that older adults are not interested in technology [19]. Even among Telecare providers there is often an over-estimation of the amount of 'technophobia' experienced by older users of Telecare [20]. Older generations are gaining more computer-related knowledge and are becoming more accustomed to technology [1420], yet still the majority of technological interfaces are not designed with older users in mind [21]. This leads us to question whether older generations have been abandoned in the technological revolution.

The design of technologies is vital. For example the physical features of a piece of technology, such as size, shape and durability, impact the likelihood that the piece of technology will be used, and how it will be used [18]. The connotations embodied by the iPad are modernity, status, independence and youth, compared to those embodied by Telecare alarms, namely decay, dependence and loss of youth [18]. Several of our participants were aware of recent technological developments, including third generation Telecare systems. As early as 2004 Demiris et al. [21] investigated older people's attitudes towards and perceptions of 'smart home' technologies and found these to be positive overall. However there are elements which require further development and evaluation, for example in recognising which behaviour patterns are normal or abnormal [4 22].

One participant suggested incorporating Telecare functions within smartphones. One question raised by our research is whether this generation of potential future Telecare users, who are interested in and em- brace new technologies when they are needed/useful, will accept the pendant alarm. Telecare design should not be stigmatising, yet should be personalisable to an individual's varying needs and capabilities, which is a challenging balance to achieve [14]. Greenhalgh et al. [18] suggest that the routine ability of smartphones and tablets to allow the user to select specific blocks of functionality ('apps') allows for built in adaptability and personalisation (in accordance with the 'bricolage' concept). It is possible that this ability would overcome a core barrier of Telecare, by allowing users more personalisation and choice. Innovation within Telecare takes time due to the vulnerability of users and the characteristics of the Telecare service inherently preventing rapid change [23]. Hence the field requires a rethink in terms of design for older adults.

However, as stated by our participants, the most important consideration in a person's decision to use a piece of technology is that the equipment, and the team behind the equipment, are reliable and operate as they should.

\subsection{Alternative options}

Whilst it is true that a greater proportion of assistive technology users are in the older age groups [24], older people do not passively use technology [25], and many will proactively seek solutions to restrictions or impairments [1826]. Our participants used a range of technological alternatives to Telecare, including smoke and carbon monoxide alarms and mobile phones. Although there were recognised disadvantages to using technology which was not wired into a 24-hour call service, such as compromised safety and greater reliance on family members, alternatives did offer distinct advantages for our participants. A key advantage was financial, in that alternatives were deemed to be lower cost, with a simpler payment method (usually a one-off cost), and were easily available in shops. In addition it might be argued that devices such as smoke alarms and mobile phones are used by people of all age groups and do not carry the same stigma that Telecare does, thus they may be more acceptable options.

Previous research has shown that individuals and/or family members may decide to make modifications to a piece of assistive technology, or to the way that it is used. Whilst this arguably invalidates the purpose of the technology and makes it more unreliable (e.g. pendant alarm not worn all of the time), these modifications can make the technology more functional or acceptable for the user [18]. Sanders et al. [5] emphasised 
that interventions such as Telecare should be tailored to fit in with an individual's needs, preferences and life circumstances so that they are more likely to wish to use it.

\subsection{Awareness}

A recent YouGov survey [27] found that $91 \%$ of adults in the UK had never heard of Telecare. In common with other Telecare barriers research, e.g. the MATCH project [20], our participants had low awareness not only of Telecare, but also of many of its perceived key strengths, namely the range of devices available, the different wearability options for the pendant alarm, and the age ranges in which it can be used. The recently-reported results of the AKTIVE project [17|26 28] demonstrated that, even after installation, users often have little knowledge of how the equipment works, the circumstances in which it can be used, and the type of response to expect (potentially exacerbated by the fact that Telecare is often installed during a time of crisis). According to Greenhalgh et al. [18], in order for an item of technology to be successfully used an individual first needs to be aware that the technology exists. In addition, concerns regarding the usability of technological interventions, which are frequently based on misunderstandings, have been shown to negatively impact their adoption and use [5]26]. It is notable that the Telecare industry and Telecare users have different terms of reference for the same intervention, which has implications for efforts to raise awareness of Telecare.

\subsection{Cost}

Changes are taking place in the way that Telecare is financed. Despite the UK Government's push for widespread mainstreaming of Telecare there is little robust evidence demonstrating the efficacy and costeffectiveness of the intervention [29]. Additional challenges include reduced social care budgets, determining where cost savings can be made through Telecare use, and if so who should pay [14]. Thus future funding of Telecare remains uncertain. Even during the course of our study Telecare funding for the most vulnerable users was withdrawn, meaning that all Telecare users in the region are now self-funded. There is an increased expectation of Telecare users to fund the service from their personal monetary resources, and as a result an additional Cost-related barrier has come into play. Financial resources significantly impact what people can afford and how much independence they can 'buy' [18]. Some people who could benefit from Telecare may simply not be able to afford it without foregoing essentials such as food and heating. Therefore the intervention must be affordable for the end user [14].

However our research suggests that if the perceived need for Telecare is strong enough then people will pay for it if they can afford it. Traditionally Telecare provision and use has been implemented through Local Authorities, which has stifled redesign and reshaping of services [10]. We hypothesise that the field will develop more characteristics of a consumer market, with individuals making a decision about whether a piece of Telecare, and the service behind it, is worthwhile for them to spend their money on. In which case Telecare design would need to become more appealing and tackle its associated stigma in order to attract consumers. Telecare-based design modifications are difficult to finance and implement [7], but would a consumer market change that?

\subsection{Safety versus independence}

To summarise, the findings of our study suggest that people's decisions regarding the use of Telecare are underpinned by a consideration of safety versus independence. At first glance it appears that independence and safety are antagonistic and an increase in one results in compromises in the other. However terms such as these do not need to be contradictory [13]17], as shown by the fact that our participants frequently used alternatives to Telecare which enhanced safety whilst losing the stigma of old age and lost independence. Older people are not just passive recipients, but are increasingly becoming consumers of technology and social care services [14]. Our participants wanted to make decisions for themselves, as part of maintaining their independence. This is also reflected in the way people modify technology to suit their needs, which arguably increases risk but also increases relevance and individuality. There is an assumption that people want to protect themselves from risk all of the time, whereas the reality may be that people want to assess the risk for themselves [930].

\subsection{Future directions}

An ageing population and increased life expectancy have led to a focus on empowering older people to lead fulfilling and autonomous lives, which may al- 
ter the demand for products and services within older age groups [1921]. Our findings are consistent with those of other research projects and add to the call for transformation of the way Telecare is designed, marketed and delivered to older people [17]. People need to make their own choices about which technologies are useful and relevant to them [5[10], which should be facilitated through the provision of sophisticated, safe and personalisable options (e.g. Telecare via smartphone apps) rather than generically providing people with stigmatising pendant alarms.

\subsection{Strengths and weaknesses}

This study reports the perceptions of individuals who might be deemed eligible for Telecare but who were not current users of it, or who had behaviourally rejected it. This perspective is one which is rarely heard in research on barriers to Telecare use but is vital in understanding how to widen the reach of Telecare, in accordance with UK Government initiatives. In addition we attempted to include the perspectives both of those who rejected Telecare outright and those who rejected it through not considering it or not even being aware of it in the first place. However a potential weakness of the study lies in the fact that our sample was self-selected and incentivised, thus they may not have been representative of potential Telecare users in general. However self-selection is a common, and in this case unavoidable, disadvantage of research projects.

\section{Conclusions}

Our findings indicate, first of all, that barriers to Telecare use are similar for both users and non-users of Telecare, including stigma, awareness and suitability of design. Secondly, our results indicate that designrelated barriers which were identified twenty years ago have yet to be addressed despite significant advances in technology. In addition, budgetary restrictions mean the cost model of Telecare services is evolving, whereby users of the service are frequently expected to self-fund the intervention. With Telecare becoming more and more driven by a consumer model, the same attention to design and to advances in technology which are given to younger audiences should be given to older people as well in order to improve their lives and their wellbeing, and most importantly allow them to maintain their choice and independence.

\section{Acknowledgements}

This project was kindly supported by Sheffield Hospitals Charity (Registered Charity No.1059043) via NIHR CLAHRC for South Yorkshire.

This article presents independent research by the National Institute for Health Research Collaboration for Leadership in Applied Health Research and Care for South Yorkshire (NIHR CLAHRC SY). The views and opinions expressed are those of the authors, and not necessarily those of the NHS, the NIHR, or the Department of Health.

CLAHRC SY would also like to acknowledge the contributions of partner organisations and particularly those of the participants from this study.

\section{References}

[1] Bower P, Cartwright M, Hirani SP, Barlow J, Hendy J, Knapp $\mathrm{M}$, et al. A comprehensive evaluation of the impact of telemonitoring in patients with long-term conditions and social care needs: protocol for the whole systems demonstrator cluster randomised trial. BMC Health Services Research. 2011; 11: 184. doi:10.1186/1472-6963-11-184.

[2] Department of Health. Building telecare in England; 2005. Available from: http://webarchive.nationalarchives.gov.uk/20 130107105354/http://www.dh.gov.uk/en/Publicationsandstati stics/Publications/PublicationsPolicyAndGuidance/DH_4115 303.

[3] Department of Health. A concordat between the Department of Health and the telehealth and telecare industry; 2012. Available from: https://www.gov.uk/government/publications /concordat-between-the-department-of-health-and-the-tele health-and-telecare-industry.

[4] Brownsell S, Blackburn S, Hawley MS. An evaluation of second and third generation telecare services in older people's housing. Journal of Telemedicine and Telecare. 2008; 14(1): 8-12. doi:10.1258/jtt.2007.070410.

[5] Sanders C, Rogers A, Bowen R, Bower P, Hirani S, Cartwright M, et al. Exploring barriers to participation and adoption of telehealth and telecare within the Whole System Demonstrator trial: A qualitative study. BMC Health Services Research. 2012; 12: 220. doi:10.1186/1472-6963-12-220.

[6] Hanson J, Percival J, Aldred H, Brownsell S, Hawley M. Attitudes to telecare among older people, professional care workers and informal carers: A preventative strategy or crisis management? Universal Access in the Information Society. 2007; 6(2): 193-205. doi:10.1007/s10209-007-0075-y.

[7] Thornton P, Mountain G. A positive response: developing community alarm services for older people. Joseph Rowntree Foundation and Community Care: York: London, 1992.

[8] Doughty K, Lewis R, McIntosh A. The design of a practical and reliable fall detector for community and institutional telecare. Journal of Telemedicine and Telecare. 2000; 6(1): 1504. doi:10.1258/1357633001934483.

[9] Stowe S, Harding S. Telecare, telehealth and telemedicine. European Geriatric Medicine. 2010; 1: 193-7. doi:10.1016/j. eurger.2010.04.002. 
[10] Mort M, Roberts C, Callén B. Ageing with telecare: Care or coercion in austerity? Sociology of Health \& Illness. 2013; 35(6): doi:10.1111/j.1467-9566.2012.01530.x.

[11] Office of National Statistics. Focus on the digital age; 2007. Available from http://www.ons.gov.uk/ons/rel/social-trends$\mathrm{rd} /$ focus-on-the-digital-age/2007-edition/index.html.

[12] Burford S, Park S. The impact of mobile tablet devices on human information behaviour. Journal of Documentation. 2014; 70(4): 1-23.

[13] Boström M, Kjellström S, Björklund A. Older persons have ambivalent feelings about the use of monitoring technologies. Technology and Disability. 2013; 25(2): 117-125. doi:10.3233/TAD-130376.

[14] Turner KJ, McGee-Lennon MR. Advances in telecare over the past 10 years. Smart Homecare Technology and TeleHealth. 2013; 1: 21-34. doi: http://dx.doi.org/10.2147/SHTT.S42674.

[15] Richie J, Spencer L. Qualitative data analysis for applied policy research. In: Bryman and Burgess, editors. Analysing Qualitative Data. London: Routledge; 1994. p. 173-94.

[16] Milligan C, Roberts C, Mort M. Telecare and older people: who cares where? Social Science \& Medicine. 2011; 72: 347 54. doi:10.1016/j.socscimed.2010.08.014.

[17] Hamblin K. Lifestyles in Later Life: identity, choice and stigma. 2014; http://circle.leeds.ac.uk/projects/current/ aktive/.

[18] Greenhalgh T, Wherton J, Sugarhood P, Hinder S, Procter R, Stones R. What matters to older people with assisted living needs? A phenomenological analysis of the use and non-use of telehealth and telecare. Social Science \& Medicine. 2013; 93: 86-94. doi:10.1016/j.socscimed.2013.05.036.

[19] Fisk AD, Rogers WA, Charness N, Czaja SJ, Sharit J. Designing for Older Adults: Principles and Creative Human Factors Approaches. 2nd ed. Boca Raton: CRC Press, Taylor \& Francis Group, 2009.

[20] Clark JS, McGee-Lennon M. A stakeholder centered exploration of the current barriers to the uptake of home care technology in the UK. Journal of Assistive Technologies. 2011; 5 : 12-25. doi:10.5042/jat.2011.0097.
[21] Demiris G, Rantz MJ, Aud MA, Marek KD, Tyrer HW, Skubic $\mathrm{M}$, et al. Older adults' attitudes towards and perceptions of "smart home" technologies: A pilot study. Medical Informatics \& the Internet in Medicine. 2004; 29(2): 87-94. doi:10.1080/14639230410001684387.

[22] Hanson J, Osipovic D, Hinew N, Amaral T, Curry R, Barlow J. Lifestyle monitoring as a predictive tool in telecare. Journal of Telemedicine and Telecare. 2007; 13(1): 26-8. doi: 10.1258/135763307781645040.

[23] Barlow J, Bayer S, Castleton B, Curry R. Meeting government objectives for telecare in moving from local implementation to mainstream services. Journal of Telemedicine and Telecare. 2005; 11(1): 49-51. doi: 10.1258/1357633054461723.

[24] Löfqvist C, Haak M, Slaug B. The Use of Assistive Technology in Different Age-Groups of Old People. Assistive Technology: From Research to Practice. 2013; 22-6. doi:10.3233/ 978-1-61499-304-9-22.

[25] Joyce K, Loe M. A sociological approach to ageing, technology and health. Sociology of Health \& IIlness. 2010; 32(2): 171-80. doi:10.1111/j.1467-9566.2009.01219.x.

[26] Yeandle S. Frail Older People and their Networks of Support: How does telecare fit in? 2014; http://circle.leeds.ac.uk/ projects/current/aktive/.

[27] Telehealth Forum. Research indicates public has no idea what telehealth is. 2012. Available from: http://www.telehealthfor um.org/wp-content/uploads/2012/07/Salix-TF-You-GovResearch-Release-FINAL-16-07-12.pdf.

[28] Koivunen E-R. Telecare and older people's social relations. 2014; http://circle.leeds.ac.uk/projects/current/aktive/.

[29] Barlow J, Singh D, Bayer S, Curry R. A systematic review of the benefits of home telecare for frail elderly people and those with long-term conditions. Journal of Telemedicine and Telecare. 2007; 13(4): 172-9. doi: 10.1258/1357633077 80908058 .

[30] Hamblin K. Risk, Freedom and Control in Older People's Lives: The relevance of telecare. 2014; http://circle.leeds.ac. uk/projects/current/aktive/. 